\title{
KUALITAS PRODUK DAN PELAYANAN RESTORAN CEPAT SAJI DALAM MENGHADAPI PESAING DI KABUPATEN SUMENEP (Studi Pada Toby's Fried Chicken)
}

\author{
Very Andrianingsih \\ Program Studi Manajemen, Universitas Wiraraja, Madura \\ veryandrianingsih@wiraraja.ac.id
}

\begin{abstract}
Product quality and service affect the progress of a restaurant. The rise of business competition requires businesses to continue to innovate so as not to compete. Restaurant business owners must always maintain and improve the quality of their products and services. The quality of products and services is a means to compete with competitors. Quality products and services will help restaurant business owners to get a strategic market position. This study aims to find out how the quality of Toby's Fried Chicken products and services in Sumenep Regency. The sampling technique in this study used Purposive Sampling by determining key informants as many as 1 person, 2 main informants, supporting informants as many as 5 people and using data collection techniques, including observation, interviews, and documentation. The results of this study indicate that Toby's Fried Chicken products in the latest Fried Chicken products are still undercooked, Toby's Fried Chicken has not released a variety of new products with a steady innovation. The service of Toby's Fried Chicken is quite good with the good attitude shown by the waiter, but for the arrangement of the place there is no attractive design to be enjoyed by customers. Toby's Fried Chicken continues to maintain and improve its quality, both in terms of products and services to be able to compete with fast-food restaurants like Toby's.
\end{abstract}

Keywords : Product Quality And Service

\begin{abstract}
ABSTRAK
Kualitas produk dan pelayanan mempengaruhi kemajuan sebuah restoran. Maraknya persaingan bisnis menuntut para pelaku usaha untuk terus melakukan inovasi agar tidak kalah bersaing. Pemilik usaha restoran harus selalu menjaga dan ditingkatkan kualitas produk dan layanannya. Kualitas produk dan pelayanan merupakan sarana untuk dapat bersaing dengan pesaingnya. Produk dan pelayanan yang berkualitas akan membantu para pemilik usaha restoran untuk mendapatkan posisi pasar yang strategis. Penelitian ini bertujuan untuk megetahui bagaimana kualitas produk dan pelayanan Toby's Fried Chicken di Kabupaten Sumenep. Tehnik pengambilan sampel dalam penelitian ini menggunakan Purposive Sampling dengan menentukan informan kunci sebanyak 1 orang, informan utama sebanyak 2 orang, informan pendukung sebanyak 5 orang dan menggunakan tehnik pengumpulan data, diantaranya observasi, wawancara, dan dokumentasi. Hasil penelitian ini menunjukkan bahwa produk Toby's Fried Chicken pada produk Fried Chicken terkang masih kurang matang, Toby's Fried Chicken belum mengeluarkan produk baru yang bervariasi dengan setuhan inovasi. Pelayanan Toby's Fried Chicken cukup baik dengan sikap baik yang ditunjukkan oleh pelayan, namun untuk penataan tempat tidak ada desain yang menarik untuk dinikmati oleng pelanggannya. Toby's Fried Chicken terus menjaga dan memperbaiki kualitasnya, baik dari segi produk maupun pelayanan untuk dapat bersaing dengan restoran cepat saji sejenis Toby's.
\end{abstract}

Kata Kunci: Kualitas Produk dan Pelayanan

\section{PENDAHULUAN}

Pada zaman milenial seperti sekaran banyak sekali restouran siap saji atau dikenal dengan fast food yang bermunculan di berbagai kota di Indonesia. Restoran cepat saji menjadi trend gaya modern saat ini yang banyak diminati oleh masyarakat Indonesia. Restoran cepat saji di Indonesia sudah ada sejak tahun 1959. Bakmi GM menjadi restouran cepat saji pertama yang ada Indonesia dan merupakan restoran asli buatan indonesia.

Abad ke 20 menjadi awal mula munculnya restoran cepat saji. Berdasarkan sejarahnya makanan cepat saji berawal dari zaman Romawi Kuno. Berawal dari 
kehidupan kaum urban di zaman tersebut telah membuat munculnya banyak apartemen bertingkat, yang hanya memiliki area dapur yang sempit atau tidak ada sama sekali, sehingga banyak bermunculan pedagang kaki lima dan restoran yang menjual makanan. Lalu pada abad pertengahan, makanan cepat dan murah banyak tersedia di kota-kota besar di Eropa, termasuk London dan Paris yang menjual makanan cepat saji untuk penduduk lokal dan turis hingga saat ini. Mengunjungi tempat suci menjadi populer dan sektor pariwisata mengalami perkembangan pesat daripada sebelumnya. Makanan cepat saji yang murah inilah yang kemudian menjadi favorit dan populer di kalangan wisatawan. Industri makanan cepat saji terus mengalami perkembangan yang pesat. Waralaba makanan cepat saji telah menjadi tempat makan yang populer dengan begitu mudahnya. makanan cepat saji semakin menjadi favorit untuk semua kalangan.

Restoran cepat saji terus mengalami perkembangan yang pesat. Saat ini Restoran cepat saji sudah banyak menyebar di Indonesia. Beberapa Kota dan Kabupaten yang ada di Indonesia. Restouran cepat saji menjadi pilihan alternatif bagi masyarakan Indonesia. Masyarakat Indonesia memilih restouran cepat saji sebagai alternatif untung menghemat waktu yang tidak perlu menunggu lama untuk membeli maknan.

Berdasarkan Survei Master Card sebagian besar masyarakat Indonesia ternyata lebih menyukai datang ke restoran cepat saji dibandingkan jenis restoran lainnya ketika mereka ingin makan di luar rumah. Menurut survei terbaru dari Master Card bertajuk Consumer Purchasing Priorities, sebanyak 80 persen orang Indonesia, mereka memilih untuk makan di restoran cepat saji, urutan kedua ialah pusat jajanan/food court dengan persentase 61 persen, dan ketiga ialah restoran/kafe kelas menengah dengan persentase 22 persen. Sementara itu, hanya sekitar 1 persen masyarakat di Indonesia yang lebih memilih untuk berkunjung ke restoran untuk jamuan makan resmi (fine dining).

Kabupaten sumenep juga menjadi salah satu sasaran restoran cepat saji untuk membukan cabangnya. Masyarakat Sumenep merespon positif dengan keberadaah restoran cepat saji yang didirikan di Sumenep. Dengan adanya restoran cepat saji akan lebih memudahkan masyarakan ketikan ingin memesan makanan dalam waktu cepat tanpa harus menunggu lama karena harus menunggu makanannya dimasak.

Toby's Fried Chicken merupakan salah satu restoran cepat saji yang ada di Kabupaten Sumenep. Restoran ini menyediakan beberapa makanan cepat saji diantaranya ayam goreng tepung, spageti, dan yang lainnya. Dimana ayam goreng tepung menjadi produk utamanya. Diawal pembukaannyan banyak menarik minat masyakat Sumenep untuk mengunjunginya dengan tujuan ingin merasakan produk yang ditawarkan oleh Toby's Fried Chicken .

Seiring berjalannya waktu banyak para pesaing bisnis yang bermunculan di Kabupaten Sumenep. Saat ini ada beberapa restoran cepat saji yang membukan cabangnya di Kabupaten Sumenep. Hal tersebut menjadi tantangan tersendiri terhadap Toby's Fried Chicken. Toby's Fried Chicken harus mampu memberikan kualitas yang lebih baik dari para pesaingnya, baik dari segi produk maupun pelayanan.

Berdasarkan keterangan dari para konsumennya produk yang dijual di Toby's Fried Chicken mengalami penurunan kualitas. Ayam goreng tepung yang menjadi produk andalan di Toby's Fried Chicken sudah tidak sebagus di awal-awal. Ayamnya goreng tepungnya sudah tidak renyah seperti 
dulu, bahkan terkadang masih ada ayamnya yang belum sepenuhnya matang. Hal tersebut menjadi bahan pertimbangan oleh konsumen untuk membeli makanan di Toby's Fried Chiken. Sedangkan para pesaing banyak mengeluarkan produk dengan inovasi-inovasi baru yang dapat menarik minat konsumen.

Pelayanan yang diberikan oleh Toby's Frid Chicken kepada kosumennya adalah pelayanan standart. Toby's Fried Chicken tidak memiliki kreatif dalam memberikan pelayanan yang mampu menarik perhatian konsumen untuk berkunjung.

Maraknya bisnis restoran cepat saji di Kabupaten Sumenep meningkatkan persaingan bisnis yang semakin ketat, dimana para pelaku usaha harus pintar dalam mengelola usahanya. Para pengusahan restoran siap saji berlomba-lomba untuk menberikan yang terbaik kepada konsumennya agar dapat menarik konsumen agar tidak berpaling pada pesaingnya. Toby's Fried Chicken harus mampu mempertahankan eksistensinya sebagai restoran cepat saji yang awal di Kabupaten Sumenep. Berdasarkan latar belakang yang telah diuraian diatas, penulis berkeinginan untuk melakukan penelitian dengan judul : "Kualitas Produk Dan Pelayanan Restoran Cepat Saji Dalam Menghadapi Pesaing Di Kabupaten Sumenep (Studi Pada Toby's Fried Chicken )"

\section{METODOLOGI PENELITIAN}

Jenis penelitian ini adalah penelitian kualitatif. Peneliti sebagai instrumen dalam mendeskripsikan kualitas produk dan pelayanan Toby's Fried Chicken dalam menghadapi pesaing di Kabupaten Sumenep. Peneliti menggambarkan bagaimana kualitas dan pelayanan yang dimiliki oleh Toby's Fried Chicken untuk menghadapi pesaingnya.
Tehnik pengambilan sampel yang digunakan pada penelitian ini iyalah purposive sampling atau sampel bertujuan. Dalam penelitian ini peneliti menentukan beberapa informan untuk mendapatkan data sesuai kebutuhan.

Tehnik pengumpulan data yang digunakan dalam penelitian ini ialah observasi, wawancara, dan dokumentasi agar dapat meningkatkan kekuatan data.

Peneliti melakukan analisis data dari informasi awal yang didapatkan dari ojek penelitian terkait dengan topik penelitian. Analisis tersebut menentukan fokus penelitian yang akan dibahas oleh peneliti. Peneliti menfokuskan penelitianya mengenai kualitas produk dan pelayanan yang diberikan oleh Toby's Friend Chicken kepada konsumennya dalam menghadapi pesaingnya di Kabupaten Sumenep.

Peneliti mendapatkan data dari hasil observasi, wawancara, dan dokumentasi yang kemudian dirangkum, memilih hal-hal pokok, memfokuskan pada topic penelitian agar lebih terperinci. Data yang diambil adalah data-data yang sesuain dengan fokus penelitian, yaitu data yang berkaitan dengan kualitas preoduk dan pelayanan yang diberikan oleh Toby's Fried Chicken kepada konsumennya dalam menghadapi pesaingnya. Reduksi data dilakukan untuk memudahkan peneliti dalam mencari data yang memberikan sebuah gambaran yang jelas mengenai objek penelitian.

Setelah melaksanakan pengolahan data melalui reduksi data, maka selanjutnya dilakukan menyajikan data yang berupa uraian singkat mengenai topik penelitian. Penyajian data akan lebih memudahkan pembaca untuk memahami isi dari hasil penelitian. Peneliti akan menyajkan data yang berupa jawaban-jawaban dari hasil wawancara dengan responden yang telah 
dikelompokkan pada reduksi data. Verifikasi data akan menghasilkan suatu deskripsi yang menggambarkan keadaan Toby's Fried Chicken .

Data yang sudah direduksi dan disajikan akan dilakukan verifikasi data atau disimpulkan. Peneliti melakukan pemeriksaan data untuk menyimpulkan dan medapatkan gambaran objek penelitian yang menberikan jawaban dari rumusan masalah yang sudah diuraikan di awal. Kesimpulan tersebut memberikan gambaran mengenai kualitas produk dan pelayanan di Toby's Fried Chicken kepada konsumennya dalam menghadapi pesaingnya.

Pada penelitian ini digunakan uji kreadibilitas untuk menguji keabsahan datanya yaitu dilakukan dengan triagulasi. Triagulasi dalam pengujian keabsahan data ini diartikan sebagai suatu proses untuk melakukan pengecekan data melalui berbagai sumber yang berbeda, cara yang berbeda, dan waktu yang berbeda.

\section{HASIL DAN PEMBAHASAN}

a. Kualitas Produk Toby's Fried Chicken di Kabupaten Sumenep

Toby's Fried Chicken memiliki beberapa produk yang ditawarkan kepada konsumennya. Dari beberapa produk yang ditawarkan ada produk yang paling diminati oleh konsumen, seperti produk dengan menu paket. Produk yang ditawarkan oleh Toby's Fried Chicken menggunakan bahan-bahan baku yang bagus untuk tetap menjaga kualitas produknya, karena bahan baku sangat berpengaruh terhadap hasil akhir sebuah produk.

Ketepatan proses memasak juga akan berpengaruh pada kualitas produk dari sebuah restoran cepat saji. Kualitas Produk Toby's Fried Chicken yang berupa Fried Chicken atau ayam goreng tepung, terkadang kurang baik dari segi kematangan sehingga menghasilkan Fried Chicken kurang renyah. Hal tersebut akan mengakibatkan penilaian negatif dari para konsumennya.

Produk Toby's Fried Chicken memiliki kekurangan dari segi variasi produk. Sampai saat ini Toby's Fried Chicken belum menciptakan produk baru yang mampu menarik perhatian konsumen, sehingga ada beberapa konsumen yang menyarankan Toby's Fried Chicken untuk menciptakan produk baru agar dapat bersaing. Produk yang ditawarkan oleh Toby's Fried Chicken belum ada perkembangan dengan variasi-variasi baru, yang masih merupakan produk-produk yang ditawarkan sejak awal pembuakaannya.

b. Pelayanan Toby's Fried Chicken dalam melayani konsumen di Kabupaten Sumenep

Pelayanan yang di berikan oleh Toby's Fried Chicken cukup baik. Pelayan bersikap ramah dan sopan kepada pengunjung. Pihak Toby's Fried Chicken menanggapin dengan baik setiap ada komplain dari konsmennya. Toby's Fried Chicken menjadikan komplain dari konsumen sebagai masukan untuk meningkatkan kualitasnya dan mencari solusi dari komplain yang disampaikan oleh konsumen.

Fasilitas merupakan suatu bentuk pelayanan kepada konsumen, termasuk kenyamanan konsumen saat berada di Toby's Fried Chicken. Ruangan untuk konsumen di Toby's Fried Chicken akan menjadi penunjang para konsumennya untuk bisa merasakan kenyamanan berada di Toby's Fried Chicken. Penataan konsep ruang untuk konsumen di Toby's Fried Chicken kurang menarik perhatian pelanggan, sehingga ada beberapa pelanggan yang kurang nyama dan kurang tertarik dengan penataan ruangannya. 
c. Toby's Fried Chicken dalam menghadapi pesaing di Kabupaten Sumenep

Pesaing akan menjadi ancaman bagi Toby's Fried Chicken apabila Toby's Fried Chicken tidak melakukan pengembangan produk untuk tetap bertahan di hati para konsumennya. Toby's Fried Chicken menanggapi positif adanya persaingan bisnis dalam bidang restoran cepat saji. Pihak Toby's Fried Chicken menganggap para pesaingnya sebagai motivasi untuk tetap menjaga dan meningkatkan kualitasnya, baik dari kualitas produk maupun dari segi pelayanan, agar Toby's Fried Chicken dapat bersaing dengan pesaingnya dan bisa mendapatkan posisi pasar yang strategis.

Toby's Fried Chicken sudah bisa bersaing dengan pesaingnya, namun baik produk maupun pelayanannya perlu adanya pengawasan untuk tetap menjaga kualitas dan meningkatkan kualitas agar tidak kalah dalam bersaing. Toby's Fried Chicken sampai saat ini Toby's Fried Chicken belum megeluarkan produk-produk baru untuk menyaingi para pesaingnya, sementara para pesaingnya hadir dengan produk-produk baru yang menjadi andalannya. Di tengah maraknya persaingan bisnis restoran cepat saji sejenis Toby's Fried Chicken, Toby's Fried Chicken dituntut untuk bisa meningkatkan kualitas produk dan pelayanannya, serta menciptakan produkproduk dengan variasi baru.

\section{KESIMPULAN}

Berdasarkan hasil penelitian dan pembahasan diatas maka peneliti akan menarik simpulan yang terkait dengan penelitiannya sebagai berikut :

a. Kualitas Produk Toby's Fried Chicken di Kabupaten Sumenep

Kualitas produk Toby's Fried Chicken cukup baik. Toby's Fried Chicken menggunakan bahan baku yang bagus untuk menjaga kualitas produknya. Produk Toby's Fried Chicken memiliki kekurarangan yaitu pada pada proses pengolahan, terkadanng produk Fried Chicken dari Toby's Fried Chicken kurang matang, sehingga kurang renyah. Toby's Fried Chicken sampai saat ini belum mengeluarkan produk-produk baru yang bervariasi dengan sentuhan inovasi yang dapat menarik konsumen untuk mengunjungi Toby's Fried Chicken

b. Pelayanan Toby's Fried Chicken dalam melayani konsumen di Kabupaten Sumenep

Toby's Fried Chicken memberikan pelayanan yang baik kepada konsumennya. Pelayan bersikap baik, ramah, dan santun kepada konsumen. Setiap ada komplain pihak Toby's Fried Chicken menanggapi dengan baik dan dijadikan bahan evaluasi untuk memperbaiki kualitasnya. Penataan ruang Toby's Fried Chicken yang merupakan fasilitas Toby's Fried Chicken yang diberikan kepada konsumen dan merupakan bagian dari pelayanan Toby's Fried Chicken kurang menarik bagi konsumen.

c. Toby's Fried Chicken dalam menghadapi pesaing di Kabupaten Sumenep

Toby's Fried Chicken menganggap para pesaingnya sebagai motivasi untuk meningkatkan kualitasnya dalam segala aspek baik dari segi produk maupun pelayanan. Toby's Fried Chicken sudah bisa bersaing dengan pesaingnya di Kabupaten Sumenep, namun Toby's Fried Chicken harus menjaga dan meningkatkan kualitas produknya, serta memberikan pelayanan yang maksimal agar dapat bersaing dengan pesaingnya dan mendapatkan pasisi pasar yang strategis.

\section{DAFTAR PUSTAKA}

Amanah, Dita, 2010. pengaruh harga dan kualitas produk terhadap kepuasan konsumen pada majestyk bakery \& 
cake shop cabang h.m. yamin medan. Jurnal Keuangan dan bisnis. Vol. 2 No. 1.

Horax, M, Sanjaya, L, Pratiwi, J, Yosephien, A, K,. 2017. Analisis Kepuasan Konsumen terhadap Pelayanan Restoran Cepat Saji (Restoran X) dengan Metode Service Quality (Servqual). Jurnal metris 18. ISSN.

Herman, 2017. Manajemen pemasaran. ALFABETA Bandung.

Kotler philip, \& Hoang, S, A,. 2003. Manajemen pemasaran sudut pandang asia edisi bahasa indonesia, PT. indeks gramedia, jakarta.

Kotler, philip, 2003. Marketing Manajemen international edition, prentice hall. inc, new jersey.

Machfoed, M, 2015. Kewirausahaan. Yogyakarta. BPEE.

Nyoman, N, R,. 2011. Strategi Meningkatkan Kualitas Produk Untuk Menang Dalam Kompetisi. Jurnal Sains dan tenologi. Vol. 10 No. 3.

Nasution, MN, 2001. Manajemen mutu terpadu. Jakarta. erlangga.

Saputro, R, 2008. Analisis pengaruh kualitas produk,kualitas pelayanan dan kepercayaan pelanggan terhadap loyalitas pelanggan ( studi kasus PT. Nusantara sakti demak). SKRIPSI UNIVERSITAS DIPONEGORO.

Sugiono. 2009. Memahami Pernelitian Kualitatif. Alfabeta, Bandung.

Sugiono. 2011. Metodelogi Penelitian Kuantitatif, Kualitatif, R \&D. Alfabeta, Bandung.

Yusak,M, A, \& Maria, M,. 2013. Pengaruh kualitas produk dan kualitas layanan terhadap kepuasan konsumen KING CAKE. Jurnal Manajemen Teori dan terapan. Vol. 6 No. 1.
Widjoyo, S, P,. \& Semuel, H, MS. 2014. pengaruh kualitas layanan dan kualitas produk terhadap kepuasan pelanggan dan loyalitas konsumen restoran happy garden surabaya. Jurnal manajemen pemasaran. Vol. 2 No. 1. 